\title{
Obstetrics outcomes of pregnancy with uterine fibroids in tertiary care hospital
}

\author{
Asima Afzal, Samina Ashraf, Waseeqa Nigeen \\ Corresponding author: Dr. Asima Afzal, Consultant Department of Gynaecology and Obstetrics \\ Lalla ded hospital, GMC Srinagar Jammu and Kashmir India. Email: drasmamantoo@gmail.com
}

Distributed under Attribution-Non Commercial - Share Alike 4.0 International (CC BY-NC-SA 4.0)

\begin{abstract}
Aim: To determine the clinical profile and obstetric outcomes among the pregnant women with uterine fibroids. Methods: This prospective observational study was carried out over a period of $1 \frac{1}{2}$ years from July 2018 to Jan 2020.96 pregnant patients with uterine fibroids were included in the study. Various parameters like maternal age, parity, number and size of fibroids, obstetric complications and mode of delivery were noted. Complete clinical examination and routine investigations were performed at each antenatal visit. Ultrasonograpy was done during each visit for fetal assessment and to observe the change in the size of the fibroid. Results: Out of 96 patients recruited, 85 of them completed the study. The mean age of patients was $32.56 \pm 4.3$ years, primigravida was $27.05 \%$, multigravida was $72.94 \%$. Spontaneous conception was seen in $75.29 \%$ and $24.70 \%$ used assisted reproductive treatment for conception. Spontaneous abortion was seen in $11.76 \%$, premature delivery in $18.7 \%$, and full term delivery in $81.3 \%$. Caesarean section was performed in $74.67 \%$ of cases and normal vaginal delivery in $25.33 \% .12 .9 \%$ had threatened miscarriage, $18.7 \%$ had preterm labour, $5.3 \%$ had antepartum bleeding due to placenta previa, 11(14.67\%) had postpartum haemorrhage.Intramural location and multiple fibroids were associated with increased risk of caesarian section as compared to sub serosal fibroids and single fibroids. Conclusions: Uterine fibroids in pregnancy are associated with higher risk of adverse obstetric complications. Regular check up is advised during antenatal period to detect any adverse obstetric complications, which will help to improve the outcome.
\end{abstract}

Keywords: Fibroid, abortion, caesarian section, postpartum haemorrhage.

Uterine fibroids are one of the most commonly encountered benign tumours of the female reproductive tract. ${ }^{1}$ The prevalence of uterine fibroids are underestimated as most of them are asymptomatic. ${ }^{2}$ The prevalence of uterine fibroids in pregnant woman ranges from $1 \%$ to $10.7 \%$. ${ }^{3,4}$ The prevalence of uterine fibroids during pregnancy is increasing as more and more women delay child bearing to later in life and incidence of uterine fibroids increases with age. ${ }^{5}$ Despite increasing incidence, the relationship between uterine fibroids and adverse obstetrics outcomes is not clearly understood. Many studies have shown that uterine fibroids can be related to lot of pregnancy complications like spontaneous abortion, placental abruption, antepartum haemorrhage, fetal malpresentation, preterm birth, premature rupture of membranes, dysfunctional labor, puerperal infection, increased need of caesarean section and postpartum haemorrhage. ${ }^{6-10}$ The main aim of our study was to assess the impact of uterine fibroids on obstetric outcomes.

\section{Material and methods}

This prospective study was carried out in tertiary care hospital over a period of $1 \frac{1}{2}$ years from July 2018 to

Received: $28^{\text {th }}$ March 2020. Peer review completed: $20^{\text {th }}$ June 2020, Accepted: $26^{\text {th }}$ June 2020.

Afzal A, Ashraf S, Nigeen W. Obstetrics outcomes of pregnancy with uterine fibroids in tertiary care hospital. The New Indian Journal of OBGYN. 2021; 7(2): 153-56. 
The New Indian Journal of OBGYN. 2021 (January-June);7(2)

January 2020. Ninety-six pregnant patients with USG documented uterine fibroid attending antenatal clinic were included in the study. Complete history, clinical examination and routine investigations were recorded during antenatal period. Pregnancy with fibroid was diagnosed by the first trimester scan. Ultrasonography was done at successive antenatal visits for fetal assessment and change in fibroid size or any complication. The following parameters were analysed: maternal age, gravidity, parity, number and size of fibroids, gestational age at delivery, obstetric complications (like preterm birth, malpresentation, prom, placenta previa, placental abruption and LBW), mode of delivery and birth weight of fetus. The patients having history of previous caesarian section, any surgery, uterine malformation or chronic diseases like diabetes, hypertension was excluded from the study. The statistical analysis was done by using SPSS 17 software. $P$ value of $<0.05$ was taken as significant.

\section{Results}

96 patients having pregnancy with uterine fibroids were included in the study. However only 85 patients' study could be completed as 11 patients were lost on follow up. Single fibroid was seen in $40(53.3 \%)$ patients and multiple was seen in $35(46.7 \%)$. Intramural location of fibroid was seen in $46(61.3 \%)$ patients and subserosal was seen in 29(38.7\%) patients. The mean age of the patients was $32.6 \pm 4.3$ years. The number of primigravida were $23(27.05 \%)$ and multigravidity was seen in $62(72.94 \%)$ of patients. Spontaneous conception was observed in $62(75.29 \%)$ of patients and assisted reproductive treatment was given in 21(24.70\%) patients (table 1$)$.

Table 1: Clinical characteristics

\begin{tabular}{lll}
\hline Parameters & Mean \pm SD & Percentage \\
\hline Age & $32.6 \pm 4.3$ years \\
\hline Gravidity & \multicolumn{2}{l}{} \\
\hline Primigravida & 23 & 27.05 \\
Multigravida & 62 & 72.94 \\
\hline Spontaneous conception & 64 & 75.29 \\
Assisted reproductive treatment & 21 & 24.70 \\
\hline \multicolumn{1}{c}{ Obstetrics outcomes are represented in table }
\end{tabular}

Obstetrics outcomes are represented in table 2 . 11(12.94\%) had threatened abortion, 10(11.76\%) had miscarriage in the study group. Placental abruption was seen in $3(4 \%)$ and placental previa $4(5.3 \%)$ patients, causing antepartum hemorrhage. Preterm delivery was seen in $14(18.6 \%)$ and full-term delivery in $61(81.3 \%)$ of patients. $19(25.3 \%)$ of patients had vaginal delivery and in $56(74.7 \%)$ caesarean section was performed. Post-partum hemorrhage was seen in 11(14.6\%) of patients.

Table 3 shows the relationship between fibroid number and obstetric outcomes. Placental abruption was seen 2
(2.6\%) patients having multiple fibroids and in $1(1.3 \%)$ patient having single fibroid, which was not statistically significant ( $\mathrm{p}$ value 0.607$) .3(4 \%)$ patients having multiple fibroids and $1(1.3 \%)$ having single fibroid had placenta previa, which was not statistically significant (pvalue 0.348).Preterm delivery in $6(8 \%)$ of single fibroid patients and $8(10.6 \%)$ of multiple fibroid patients was observed. No statistically significant difference was seen ( $\mathrm{p}$ value 0.563 ). $14(18.6 \%)$ of single fibroid patients and $5(6.6 \%)$ of multiple fibroid patients had vaginal delivery, which was statistically significant ( $\mathrm{p}$ value 0.038 ).

Table 2: Obstetric outcomes

\begin{tabular}{lll}
\hline Parameters & Number & Percentage \\
\hline Threatened abortion & 11 & 12.94 \\
Miscarriage & 10 & 11.76 \\
Preterm delivery & 14 & 18.7 \\
APH & & \\
Abruption & 3 & 4 \\
Placenta Previa & 4 & 5.3 \\
Full term delivery & 61 & 81.3 \\
Vaginal delivery & 19 & 25.33 \\
Caesarean delivery & 56 & 74.67 \\
PPH & 11 & 14.67 \\
\hline APH - Antepartum hemorrhage, PPH - Postpartum hemorrhage \\
\hline
\end{tabular}

Caesarean delivery was seen in 26(34.6\%) of single fibroid patients and $30(40 \%)$ of multiple fibroid patients. There was a statistically significant difference ( $p$ value $0.038)$. Postpartum hemorrhage was seen in $5(6.6 \%)$ of single fibroid patients and 6(8\%) of multiple fibroid patients. No statistically significant difference was seen ( $p$ value 0.752).

Table 3: Relationship between fibroid number and obstetric outcome

\begin{tabular}{llll} 
Parameters & Single $(\mathbf{n}=\mathbf{4 0})$ & Multiple $(\mathbf{n}=\mathbf{3 5})$ & P value \\
\hline Placental abruption & $1(1.3 \%)$ & $2(2.6 \%)$ & 0.607 \\
Placenta previa & $1(1.3 \%)$ & $3(4 \%)$ & 0.348 \\
Preterm delivery & $6(8 \%)$ & $8(10.6 \%)$ & 0.563 \\
Vaginal delivery & $14(18.6 \%)$ & $5(6.6 \%)$ & 0.038 \\
Caesarean delivery & $26(34.6 \%)$ & $30(40 \%)$ & 0.038 \\
PPH & $5(6.6 \%)$ & $6(8 \%)$ & 0.752 \\
\hline
\end{tabular}

$\mathrm{PPH}$ - Postpartum hemorrhage, Values in number and percentage, $\mathrm{P}$ value is significant if value is $<0.05$

Table 4 shows the relationship between fibroid location and obstetrics outcomes. 1 (1.3\%) patient of subserosal and 2 (2.6\%) patients of intramural fibroid had placental abruption which was not statistically significant ( $p$ value 0.99 ). Placenta previa was seen in $4(5.3 \%)$ patients only in intramural fibroids, which was statistically not significant (0.294). Preterm delivery was seen in $6(8 \%)$ patients having subserosal fibroids and 8 (10.6\%) of intramural fibroids. No statistically significant difference was found in two groups ( $p$ value 0.540 ). 13(17.3\%) of subserosal fibroid patients had vaginal delivery while $6(8 \%)$ of intramural fibroid patients had vaginal delivery which was statistically significant ( $p$ value 0.007). Caesarean section was performed 
The New Indian Journal of OBGYN. 2021 (January-June);7(2)

\begin{tabular}{llll}
\multicolumn{5}{l}{ Table 4: Relationship between fibroid location and obstetric outcome } \\
\hline Parameters & Subserosal $(\mathbf{n}=\mathbf{2 9})$ & Intramural $(\mathbf{n}=\mathbf{4 6})$ & P value \\
\hline Placental abruption & $1(1.3 \%)$ & $2(2.6 \%)$ & 0.99 \\
Placenta previa & 0 & $4(5.3 \%)$ & 0.294 \\
Preterm delivery & $6(8 \%)$ & $8(10.6 \%)$ & 0.540 \\
Vaginal delivery & $13(17.3 \%)$ & $6(8 \%)$ & 0.0007 \\
Caesarean section & $16(21.3 \%)$ & $40(53.3 \%)$ & 0.004 \\
PPH & $3(4 \%)$ & $8(10.6 \%)$ & 0.99 \\
\hline
\end{tabular}

in $16(21.3 \%)$ and $40(53.3 \%)$ of patients having subserous and intramural fibroids respectively. There was a statistically significant difference ( $p$ value 0.004 ) as more caesarean sections were seen in intramural group. Postpartum hemorrhage was seen in $8(10.6 \%)$ intramural fibroid patients and $3(4 \%)$ of subserosal fibroid. No statistically significant difference was seen in two groups ( $p$ value 0.99 ).

\section{Discussion}

The mean age of the patients was $32.6 \pm 4.3$ years, which was similar to other studies like Saleh et $\mathrm{al}^{11}$ and Egbe et al. ${ }^{12}$ This shows that uterine fibroids are more associated with advancing maternal age. The association of fibroid with increased in gravidity was similar to other studies like Saleh et $\mathrm{al}^{11}$ and Sheiner et al. ${ }^{13}$ There was an increased association of postpartum hemorrhage with uterine fibroids, which was similar to other studies like Febo et $\mathrm{al}^{14}$ and Parazzini et al. ${ }^{15}$ However few studies have shown no association between increased risk of post-partum hemorrhage and uterine fibroids like Coronado et al ${ }^{16}$ and Robert et al. ${ }^{17}$

Various studies reported a higher rate of caesarean delivery in cases of uterine fibroids like Qidwai et $\mathrm{al}^{18}$ and Stout et al. ${ }^{19}$ However contradictorily some studies have shown no association in the increased risk of caesarian section in pregnancy with fibroids. ${ }^{20-22}$

In our study we didn't find any significant difference in the occurrence of adverse obstetrics outcomes in relation to number of fibroids except for increased conversion to caesarean delivery. This was similar to study by Qidwai et $\mathrm{al}^{18}$ in terms of all adverse obstetrics outcomes except increased risk of caesarean section which was also not significant in this study.

However, Lam et $\mathrm{al}^{23}$ and Ciavattini et $\mathrm{al}^{24}$ who reported higher preterm delivery and caesarean section in multiple fibroids as compared to single fibroids.

Caesarean delivery was seen more commonly in intramural group which was similar to the study done by Zhao et al. ${ }^{25}$ However other studies like Saleh et al ${ }^{11}$ showed no difference in rate of caesarean delivery between intramural and subserosal group. However, no difference was found in other obstetrics outcomes between the intramural and subserosal group.

\section{Conclusion}

Pregnancy with uterine fibroids increases the incidence of obstetric complications in pregnant patients, so it is important to have regular checkup during the antenatal period for proper management.

\section{Conflict of interest: None. Disclaimer: Nil.}

\section{References}

1. Day Baird D, Dunson DB, Hill MC, Cousins D, Joel M. High cumulative incidence of uterine leiomyoma in black and white women: ultrasound evidence. Am J Obstet Gynecol. 2003;188:100-7.

2. Guo XC, Segars JH. The impact and management of fibroids for fertility: an evidence-based approach. Obstetrics and Gynecology Clinics of North America. 2012; 39(4): 521-33.

3. Coronado GD, Marshall LM, Schwartz SM. Complications in pregnancy, labor, and delivery with uterine leiomyomas: a population-based study. Obstetrics and gynecology. 2000; 95(5):764-9.

4. Laughlin SK, Baird DD, Savitz DA, Herring AH, Hartmann KE. Prevalence of uterine leiomyomas in the first trimester of pregnancy: an ultrasound-screening study. Obstetrics and gynecology. 2009;113 (3):630-5.

5. Drayer SM, Catherino WH. Prevalence, morbidity, and current medical management of uterine leiomyomas. International journal of gynaecology and obstetrics. 2015; 131(2):117-22.

6. Stout MJ, Odibo AO, Graseck AS. Leiomyomas at routine second-trimester ultrasound examination and adverse obstetric outcomes. Obstetrics Gynecology. 2010;116(5):1056-63.

7. Qidwai GI, Caughey AB, Jacoby AF. Obstetric outcomes in women with sonographically identified uterine leiomyomata. Obstetrics and Gynecology. 2006; 107(2 Pt 1): 376-82.

8. Ezzedine DNE. Are Women With Uterine Fibroids at Increased Risk for Adverse Pregnancy Outcome? Clin Obstet Gynecol. 2016, 59(1):119-27.

9. Ciavattini A, Clemente N, DelliCarpini G, Di Giuseppe J, Giannubilo SR, Tranquilli AL. Number and size of uterine fibroids and obstetric outcomes. The journal of maternal-fetal \& neonatal medicine. 2015; 28(4): 484-8.

10. Vergani P, Locatelli A, Ghidini A, Andreani M, Sala F, Pezzullo JC. Large uterine leiomyomata and risk of 
The New Indian Journal of OBGYN. 2021 (January-June);7(2)

cesarean delivery. Obstetrics and Gynecology. 2007; 109(2 Pt 1): 410-4.

11. Saleh HS , Mowafy HE, Abd El Hameid AA, Sherif HE, Mahfouz EM. Does Uterine Fibroid Adversely Affect Obstetric Outcome of Pregnancy? Biomed Res Int. 2018; 2018: 8367068.

12. Egbe TO, Badjang TG, Tchounzou R, Egbe EN. Uterine fibroids in pregnancy: prevalence, clinical presentation, associated factors and outcomes at the Limbe and Buea Regional Hospitals, Cameroon: a cross-sectional study. BMC Res Notes. 2018; 11(1): 889.

13. Sheiner E, Bashiri A, Levy A, Hershkovitz R, Katz M, Mazor M. Obstetric characteristics and perinatal outcome of pregnancies with uterine leiomyomas. The Journal of reproductive medicine. 2004; 49 (3):182-6.

14. Febo G, Tessarolo M, Leo L, Arduino S, Wierdis T, Lanza L. Surgical management of leiomyomata in pregnancy. Clinical and experimental obstetrics \&gynecology. 1997; 24(2):76-8.

15. Parazzini F, Tozzi L, Bianchi S. Pregnancy outcome and uterine fibroids. Best practice \& research Clinical obstetrics \& gynaecology. 2016; 34:74-84.

16. Coronado GD, Marshall LM, Schwartz SM. Complications in pregnancy, labor, and delivery with uterine leiomyomas: a population-based study. Obstetrics and gynecology. 2000; 95(5):764-9.

17. Roberts WE, Fulp KS, Morrison JC, Martin JN Jr. The impact of leiomyomas on pregnancy. The Australian \& New Zealand journal of obstetrics \& gynaecology. 1999; 39(1):43-7.

18. Qidwai GI, Caughey AB, Jacoby AF. Obstetric outcomes in women with sonographically identified uterine leiomyomata. Obstetrics and gynecology. 2006; 107(2 Pt 1):376-82.

19. Stout MJ, Odibo AO, Graseck AS, Macones GA, Crane JP, Cahill AG. Leiomyomas at routine second- trimester ultrasound examination and adverse obstetric outcomes. Obstetrics and gynecology. 2010; 116(5):1056-63.

20. Noor S, Fawwad A, Sultana R, Bashir R, Quratul a, Jalil $\mathrm{H}$, et al. Pregnancy with fibroids and its and its obstetric complication. Journal of Ayub Medical College, Abbottabad. 2009; 21(4):37-40.

21. Rosati P, Exacoustos C, Mancuso S. Longitudinal evaluation of uterine myoma growth during pregnancy A sonographic study. Journal of ultrasound in medicine. 1992; 11(10):511-5.

22. Moise KJ Jr. Ultrasound diagnosis of uterine myomas and complications in pregnancy. Obstetrics and gynecology. 1993; 82(5):881-2.

23. Lam SJ, Best S, Kumar S. The impact of fibroid characteristics on pregnancy outcome. American Journal of Obstetrics \&Gynecology. 2014; 211(4): 395.e1-5.

24. Ciavattini A, Clemente N, Delli Carpini G, Di Giuseppe J, Giannubilo SR, Tranquilli AL. Number and size of uterine fibroids and obstetric outcomes. E Journal of Maternal-Fetal and Neonatal Medicine. 2015; 28(4): 484-8.

25. Zhao R, Wang X, Zou L, Li G, Chen Y, Li C, et al. Adverse obstetric outcomes in pregnant women with uterine fibroids in China: A multicenter survey involving 112,403 deliveries. PLoS ONE. 2017; 12(11): e0187821.
Asima Afzal ${ }^{1}$, Samina Ashraf ${ }^{2}$, Waseeqa Nigeen ${ }^{3}$
${ }^{1}$ Consultant Department of Gynaecology and Obstetrics Lalla ded hospital, GMC Srinagar, Jammu and Kashmir, India; ${ }^{2}$ Consultant Department of Gynaecology and Obstetrics Lalla ded hospital, GMC Srinagar, Jammu and Kashmir, India; ${ }^{3}$ Medical Officer, J\&K Health Services, India. 